\title{
Engineering a minimal cloning vector from a pUC18 plasmid backbone with an extended multiple cloning site
}

Jens Staal*,1,2 Kübra Alci $^{2,3}$, Wouter De Schamphelaire ${ }^{2,3}$, Martine Vanhoucke ${ }^{2,3}$ \& Rudi Beyaert ${ }^{1,2,3}$

\section{ABSTRACT}

Minimal plasmids play an essential role in many intermediate steps in molecular biology. For example, they can be used to assemble building blocks in synthetic biology or be used as intermediate cloning plasmids that are ideal for PCR-based mutagenesis methods. A small backbone also opens up for additional unique restriction enzyme cloning sites. Here we describe the generation of $\mathrm{pICOz}$, a 1185-bp fully functional high-copy cloning plasmid with an extended multiple cloning site. We believe that this is the smallest high-copy cloning vector ever described.

\section{METHOD SUMMARY}

We eliminated all superfluous sequences in a commonly used cloning vector in order to generate as small a cloning plasmid as possible by simple iterative PCR mutagenesis.

\section{KEYWORDS:}

cloning $\cdot$ Escherichia coli $\cdot$ minimalism - mutagenesis - PCR • plasmids • recombination $\cdot$ repository $\cdot$ synthetic biology $\cdot$ synthetic nucleotide

'VIB-UGent Center for Inflammation Research, Unit of Molecular Signal Transduction in Inflammation, VIB, Ghent, Belgium; ${ }^{2}$ Department of Biomedical Molecular Biology, Ghent University, Ghent, Belgium; ${ }^{3}$ BCCM/GeneCorner, Ghent University, Ghent, Belgium; *Author for correspondence: Jens.Staal@irc.vib-ugent.be

BioTechniques 66: 254-259 (June 2019) 10.2144/btn-2019-0014

\section{GRAPHICAL ABSTRACT}

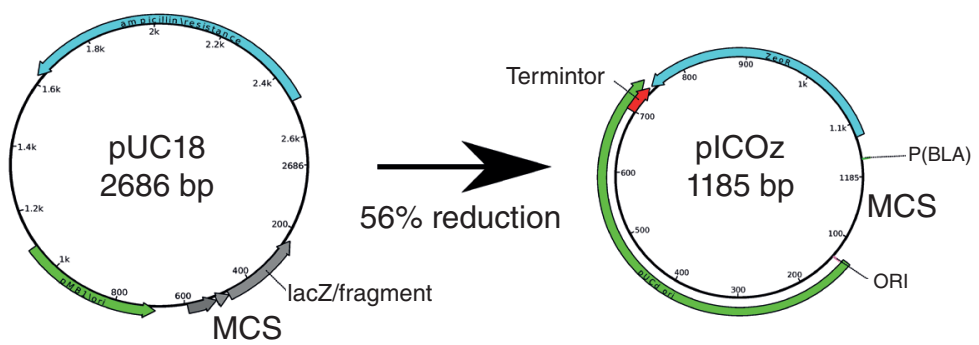

Minimal plasmids have many uses and can either be generated synthetically [1] or by iterative deletions in an existing plasmid. The pUC family [2,3] of plasmids have been extensively used as a backbone for various cloning and expression vectors [4]. One of the most attractive features of the pUC family of plasmids is that they harbor a mutated pMB1 origin of replication (ORI), which leads to very high-copy replication of the plasmid [5].

Minimalism is an artistic as well as a functional design ideal [6] that provides enhanced robustness and utility in many fields of engineering (often referred to as the KISS principle, an acronym with many different interpretations but with the same essential meaning: keep it small and simple). The ideal is often summarized by a quote from the French poet Antoine de Saint Exupéry: "It seems that perfection is attained not when there is nothing more to add, but when there is nothing more to remove" [7]. In the software world, useless code and functions are often referred to as 'bloat', and some software projects have simplicity and minimalism as core values in their development philosophy $[8,9]$. Just like useless and bloated code in software, superfluous genetic material in plasmids can cause 'bugs', like the unintended eukaryotic transcription factor binding sites present in the pUC plasmids $[10,11]$.

We have therefore applied the minimalistic philosophy in the design of a high-copy cloning plasmid backbone with as little 'bloat' as possible, which opens up for improved downstream applications. Minivectors have been found to be highly efficient for mammalian cell transfection [12] and in vivo for gene therapy [13]. Tiny plasmids are, however, not only found in a laboratory settings, replicating minimal plasmids down to 746 bp but have also been found in nature [14]. It is, however, still unclear how useful these natural minimal plasmids could be for molecular biology applications. Nevertheless, there may be further room for improvement with regards to miniaturization of useful artificial plasmids, which we invite the research community to explore further in an open, distributed manner.

\section{MATERIALS \& METHODS \\ Iterative deletions of pUC18}

The plasmid was reduced in size in several different reaction (Rxn) steps by PCR as outlined in Table 1. Primers were obtained from Invitrogen. The in silico cloning, graphical vector map generation and sequence analyses were done in UGENE (http://ugene.net) [15]. Phusion DNA polymerase (New England Biolabs) PCR reactions were performed with the following general program: $3 \mathrm{~min}$ at $98^{\circ} \mathrm{C}$ denaturation, $35 \times\left(10 \mathrm{~s} 98^{\circ} \mathrm{C}\right.$ denaturation, $20 \mathrm{~s}$ at $57^{\circ} \mathrm{C}$ annealing, $20 \mathrm{~s} / \mathrm{kbp}$ at $72^{\circ} \mathrm{C}$ elongation), $10 \mathrm{~min}$ at $72^{\circ} \mathrm{C}$. The Universe DNA polymerase (Biotool) PCR progam was 5 min at $95^{\circ} \mathrm{C}$ denaturation, $35 \times\left(20\right.$ s at $95^{\circ} \mathrm{C}$ 
Table 1. Overview of primers used in the iterative shrinking of pUC18 into pICOz.

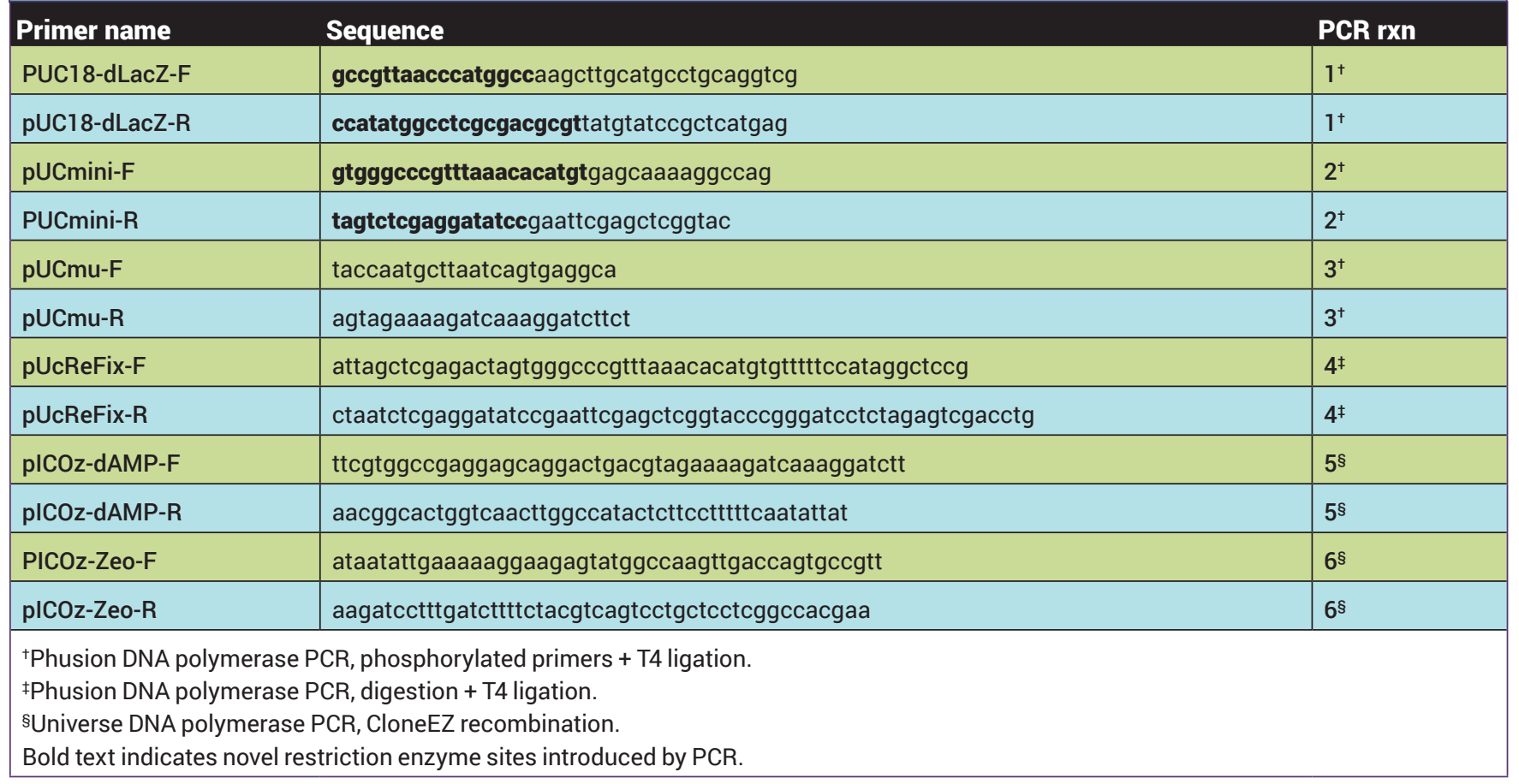

\section{Table 2. Overview of strains used in the plasmid DNA yield study.}

\begin{tabular}{|c|c|c|}
\hline Strain name & Genotype & Source \\
\hline E. coli B BL21 & FompT gal dcm lon hsdS $S_{B}\left(r_{B}^{-} m_{B}^{-}\right)\left[m a l B^{+}\right]_{\mathrm{K}-12}\left(\lambda^{s}\right)$ & Stratagene \\
\hline E. coli K12xB DB3.1 & $\begin{array}{l}\text { F-gyrA462 end } A 1 \Delta(s r 1-r e c A) ~ m c r B ~ m r r ~ h s d S 20 \text { glnV44 (=supE44) ara14 galK2 lacY1 proA2 } \\
r p s L 20 \text { xyl5 leuB6 mt/1 }\end{array}$ & $\begin{array}{l}\text { BCCM/GeneCorner } \\
\text { (LMBP 4098) }\end{array}$ \\
\hline E. coli K12 DH5 $\alpha$ & $\begin{array}{l}\mathrm{F}^{-} \Delta(\operatorname{argF}-\mathrm{lac}) 169 \text { Ф80/acZ } \Delta \mathrm{M} 15 \Delta p h o \mathrm{~A} 8 \mathrm{~g} \ln \mathrm{X} 44(\mathrm{AS}) \lambda-d e o \mathrm{R} 481 \text { rfbC1 gyrA96 recA1 endA1 } \\
\text { thiE1 hsdR17 }\end{array}$ & Invitrogen \\
\hline E. coli K12 MC1061 & $\begin{array}{l}\mathrm{F}^{-} \Delta(\text { araA-leu }) 7697[\mathrm{araD139}]_{\mathrm{B} / \mathrm{r}} \Delta(\mathrm{codB}-\mathrm{lacl}) 3 \mathrm{galK16} \text { galE15(GalS) } \lambda \cdot e 14 \text { mcrA0 relA1 } \\
\text { rpsL150 spoT1 mcrB1 hsdR2 }\end{array}$ & $\begin{array}{l}\text { BCCM/GeneCorner } \\
\text { (LMBP 472) }\end{array}$ \\
\hline E. coli $\mathrm{K} 12 \mathrm{TOP} 10$ & $\begin{array}{l}\text { F-mcrA } \Delta \text { (mrr-hsdRMS-mcrBC) } 980 / a c Z \Delta M 15 \Delta \text { lacX74 recA1 araD139 } \Delta(\text { araleu)7697 galU } \\
\text { galK rpsL (StrR) endA1 nupG }\end{array}$ & Invitrogen \\
\hline
\end{tabular}

denaturation, $20 \mathrm{~s}$ at $57^{\circ} \mathrm{C}$ annealing, $45 \mathrm{~s} /$ kbp at $72^{\circ} \mathrm{C}$ elongation), $10 \mathrm{~min}$ at $72^{\circ} \mathrm{C}$ elongation on a GeneAmp 9700 (PE Biosystems) thermocycler. Ligation with T4 DNA ligase (Promega) was performed at room temperature over night. CloneEZ (GenScript) reactions were performed for $30 \mathrm{~min}$ at room temperature. All DNA products were transformed into competent MC1061 Escherichia coli by 30 s heat shock at $42^{\circ} \mathrm{C}$ in a water bath.

\section{Determination of relative yield of}

plasmid variants

Yields of the plasmids pUC18 (LMBP 7874),
pUC18deltaLacZ (LMBP 9213), pUCmu (LMBP 9329) and pICOz (LMBP 11103) were determined from MC1061 (LMBP 472), $\mathrm{DH} 5 \alpha$ (Invitrogen), DH10B (Genome Systems), BL21 (Stratagene), Top10 (Invitrogen) and DB3.1 (LMBP 4098) E. coli strains (Table 2). Each plasmid was grown in quadruplicates starting from four individual clones picked from a plate for each host strain, and plasmids were prepped from 3 (MC1061) or 5 (other strains) $\mathrm{ml}$ culture per plasmid and replicated using HQ Mini Plasmid Purification Kit (Invitrogen) (MC1061) or QIAprep Spin Miniprep Kit (QIAGEN) (other strains). DNA concentrations were determined by NanoDrop ND-8000 (ThermoFisher).

Verification, storage \& distribution of DNA material

All plasmids in this study (Table 3) were deposited to the ISO 9001 [16] compliant BCCM/GeneCorner culture collection (www.genecorner.ugent.be). All plasmids were verified by Sanger sequencing (internal sequencing facility) and restriction enzyme digestion (Promega). Genbank sequence files for pUCmu and pICOz are provided in the supplemental data. 
Table 3. Overview of plasmids used in this study.

\section{Plasmid name}

pUC18

pUC18deltaLacZ

pUCmini

pUCmu

pU6mu

pU6z

pdITz

$\mathrm{plCOz}$

pICOz-Flag-bio-mCARD11

pICOz-Flag-hCARD14

pICOz-Flag-hCARD9

pICOz-hMALT1
Source

BCCM/GeneCorner accession number

[2]

This study

This study

This study

This study

This study

This study

This study

This study

This study

This study

This study
LMBP 7874

LMBP 9213

LMBP 9221

LMBP 9329

LMBP 9491

LMBP 11144

LMBP 11273

LMBP 11103

LMBP 11222

LMBP 11223

LMBP 11224

LMBP 11225

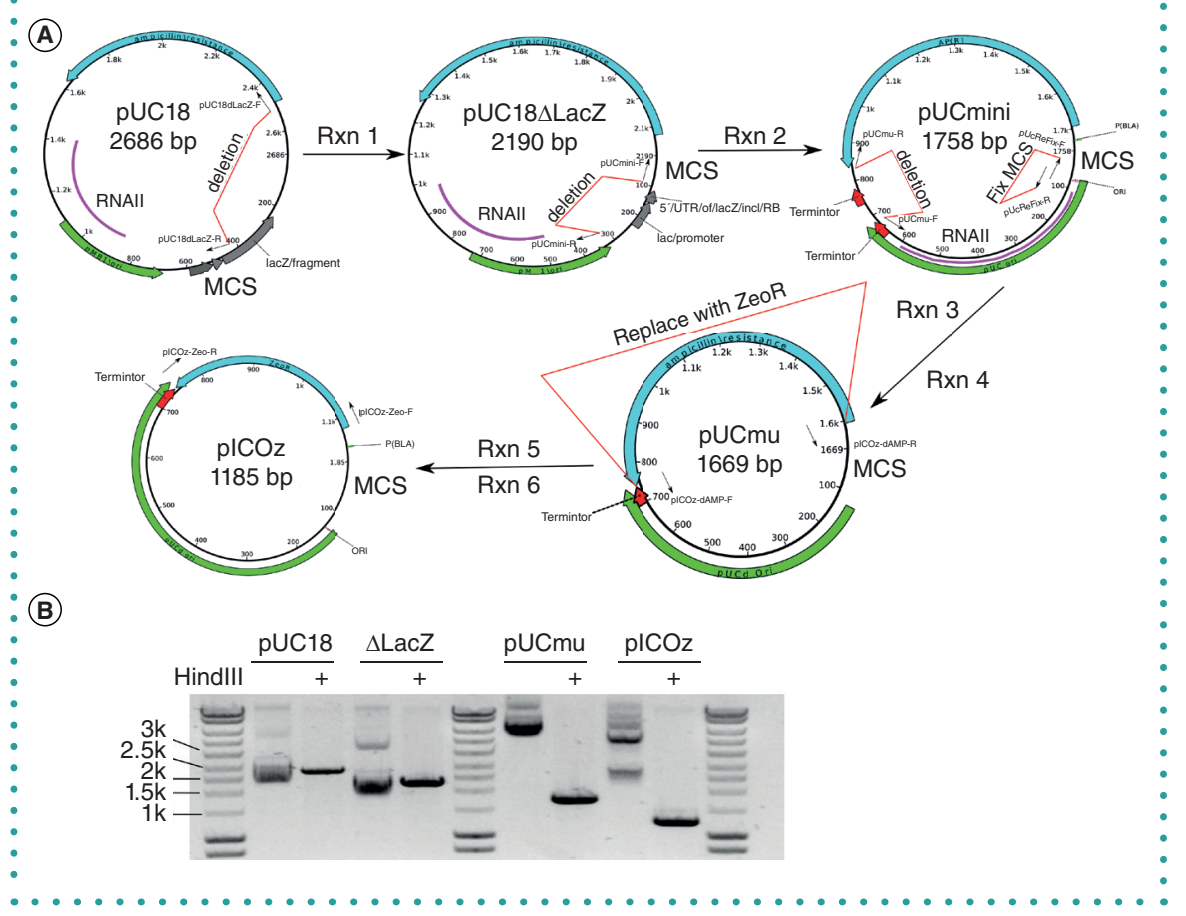

Figure 1. Overview of the cloning scheme for generation of a minimal vector backbone.

(A) Graphical overview of the modifications made in each step in the miniaturization process.

$\mathrm{Rxn}=$ reaction. Red lines indicate area that was modified in the following reaction, where the ends of the lines indicate the position of the primers used for that reaction and the black arrows indicate the primers from Table 1. Green plasmid elements indicate the annotated ORI in the plasmid; grey plasmid elements are 'useless' annotated elements; blue plasmid elements indicate antibiotic selection marker; red plasmid elements indicate annotated prokaryotic transcription terminators. The pink lines in pUC18, pUC18 LacZ and pUCmini indicate the location of the RNAll transcript, which is important for plasmid replication [5] but not included in the pMB1 ORI annotation. The new $\mathrm{ORI}$ annotation (in pUCmini, pUCmu and pICOz) after the pUCmini deletion event includes the RNAII transcript. (B) HindllI digest (indicated by ' + ') of $1 \mu \mathrm{g} \mathrm{pUC18, \Delta lacZ} \mathrm{(=pUC18 \Delta LacZ),} \mathrm{pUCmu} \mathrm{and}$ pICOz run on a $1 \%$ Agarose/TAE gel. Sizes on the SmartLadder (Eurogentec) indicated in kbp (' $k$ '). ORI: Origin of replication.

\section{- RESULTS \& DISCUSSION}

Generation of a minimal cloning plasmid with an extended multiple cloning site

In order to shrink a high-copy and widely used cloning backbone like pUC18, we sequentially eliminated code segments that we identified as unnecessary or 'useless bloat'. 'Unnecessary' is naturally a question of definition and context, where for example the LacZ present in the original pUC18 vector can be useful for performing blue/white selection during cloning. However, remnants of this sequence in expression vectors or when clone selection is done by colony PCR (for example, blue/white selection does not work in the MC1061 strain) makes this sequence unnecessary for many purposes. Consequently, the first reaction (Rxn1; Figure 1) eliminated LacZ and some additional sequence upstream of the pBla promoter driving Ampicilin resistance. The eliminated sequence was replaced by some additional restriction enzyme sites (Mlul, Nrul, Sfil, Ndel, Ncol, Mscl; Figure 2) that were added to the multiple cloning site (MCS). This resulted in pUC18deltaLacZ, which is $496 \mathrm{bp}$ smaller than the pUC18 parental plasmid.

In the second reaction (Rxn2, Figure 1), we eliminated additional parts of the LacZ promoter and useless code between the MCS and the ORI from pUC18 LacZ, and this sequence was replaced by additional restriction enzyme sites in the MCS (EcoRV, Xhol, Spel, Apal, Pmel; Figure 2). By random 
chance, a clone that was picked up showed a deletion in the pUC ORI and part of the MCS without showing any detrimental effects on plasmid yield. This event most likely was due to an alternative recombination reaction instead of the intended ligation of the plasmid PCR product. This plasmid was designated pUCmini, which is $432 \mathrm{bp}$ smaller than the pUC18 1 LacZ parental plasmid.

In order to shrink the plasmid further, an additional region with unnecessary genetic code was identified between the ampicillin resistance and the $\mathrm{ORI}$, and a deletion was made to make the resistance marker use a terminator sequence present in the ORI (Rxn 3, Figure 1). Since the pUCmini plasmid also had a deletion in the MCS, we also repaired the MCS to restore the lost restriction enzyme sites (Rxn 4, Figure 1). The resulting pUCmu plasmid ended up being 89 bp smaller than pUCmini but with a complete extended MCS. After this reaction, no 'useless bloat' genetic code could be identified in the sequence and the only way to safely shrink the plasmid further was by replacing the antibiotic selection marker with a smaller one using overlap extension cloning [17] or recombinationbased cloning. As a proof-of-concept, we replaced ampicillin resistance with zeocin resistance by amplifying the pUCmu plasmid without the ampicillin resistance sequence (Rxn 5, Figure 1) and recombined this PCR product with a PCR-amplified zeocin resistance gene (Rxn 6) using CloneEZ. In parallel, a PCR-based fusion between the two fragments was equally successful. The resulting pICOz plasmid is $484 \mathrm{bp}$ smaller than the minimal pUCmu parental plasmid. With these four sequential steps of elimination, we have thus been able to reduce the 2686-bp pUC18 plasmid to the 1185-bp pICOz plasmid, which contains more useable cloning sites, a total size reduction of $56 \%$.

Despite the history of a random deletion event during the generation of this minimal plasmid, inserts cloned and propagated in the plCOz minimal backbone are stable. We have cloned several cDNAs in pICOz as an intermediate step for PCR-based mutagenesis (e.g., MALT1 [LMBP 11225], CARD9 [LMBP 11224], CARD11 [LMBP 11222] and CARD14 [LMBP 11223]), which remain stable after multiple rounds of propagation. We have also generated generally

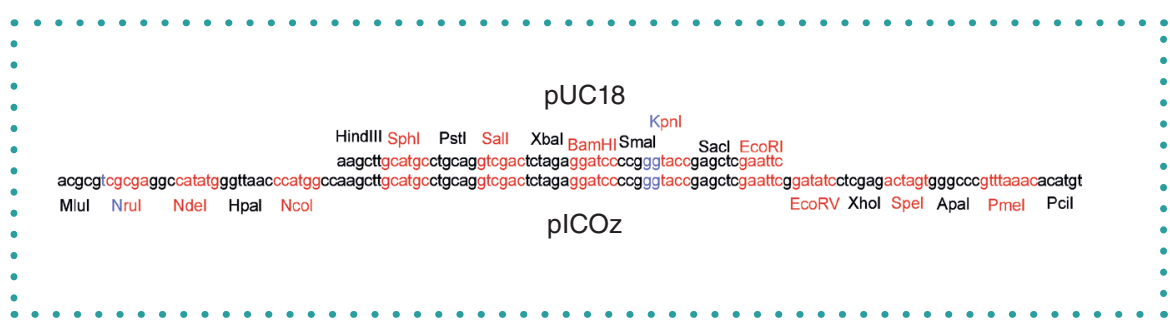

Figure 2. Comparisons of the original pUC18 MCS compared with the extended MCS in pUCmu and plCOz. Restriction sites are indicated in alternating red and black text for clarity. Overlapping nucleotides for two restriction sites are indicated in purple.

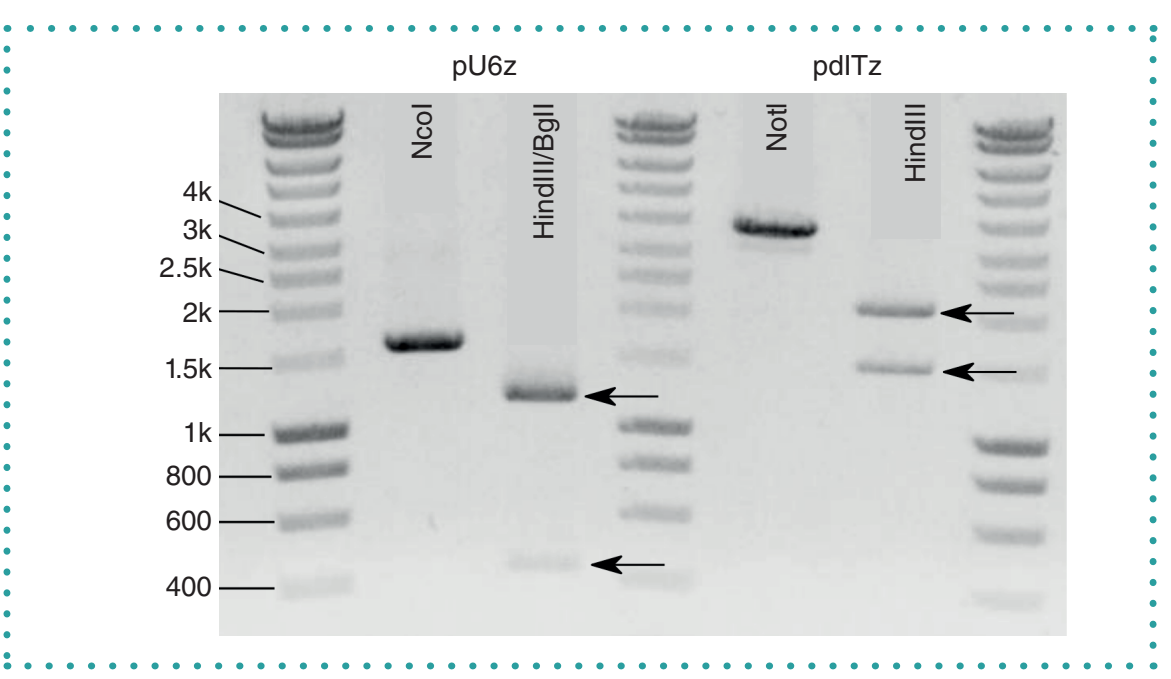

Figure 3. Verification of stability of pICOz-based clones that have been propagated several times. The pU6z plasmid was linearized with Ncol, resulting in a 1553-bp band. To verify the integrity of the remaining MCS next to the insert, a HindIII/Bgll double digest cutting in the MCS and the Zeo resistance gene was done, resulting in 1143-bp and 410-bp bands (arrows). Similarly, the pdITz plasmid with a larger insert was linearized with Notl resulting in a 3534-bp band, and part of the insert was cut out with HindIII, resulting in a 2085-bp and a 1449-bp band (arrows). Sizes on the SmartLadder (Eurogentec) indicated in kbp (' $k$ ').

useful vector backbones with a large insert, like pdITz (LMBP 11273), which contains sleeping beauty transposon arms and a multi-site gateway destination cassette, and vectors with very small inserts like the pU6z (LMBP 11144), which contains a cloning site for SpCas9 CRISPR guideRNA expression behind the $\mathrm{U} 6$ promoter. As a demonstration of stability after several rounds of amplification of these generally useful vectors, we test-digested pdITz and pU6z (Figure 3).

\section{Determination of absolute \& relative} yield of the minimal cloning plasmids In order to verify that the deletions had not eliminated anything that would impact plasmid copy number and total yield, we carried out several parallel heat shock $E$. coli transfections and mini plasmid preparations of four constructs (pUC18, pUC18 $\triangle \mathrm{LacZ}$, pUCmu and pICOz). Surprisingly, pUCmu and
pICOz show a very high yield both in absolute amount of DNA produced from an overnight culture (Figure 4A) and even more so when factoring in that these plasmids are much smaller than the pUC18 parental plasmid (Figure 4B).

\section{Generation of a minimal cloning plasmid - how small can we go?}

We describe the generation of a minimal 1-kb fully functional cloning plasmid, which is as far as we currently can get in miniaturization. All unnecessary sequences have been eliminated and there is no additional space between the MCS, ORI and selectable marker (Figure 1). We now use the smallest widely used resistance marker and the only way to shrink the plasmid further is to do additional deletion/engineering of the ORI or replace the ORI with an alternative, smaller, ORI. 


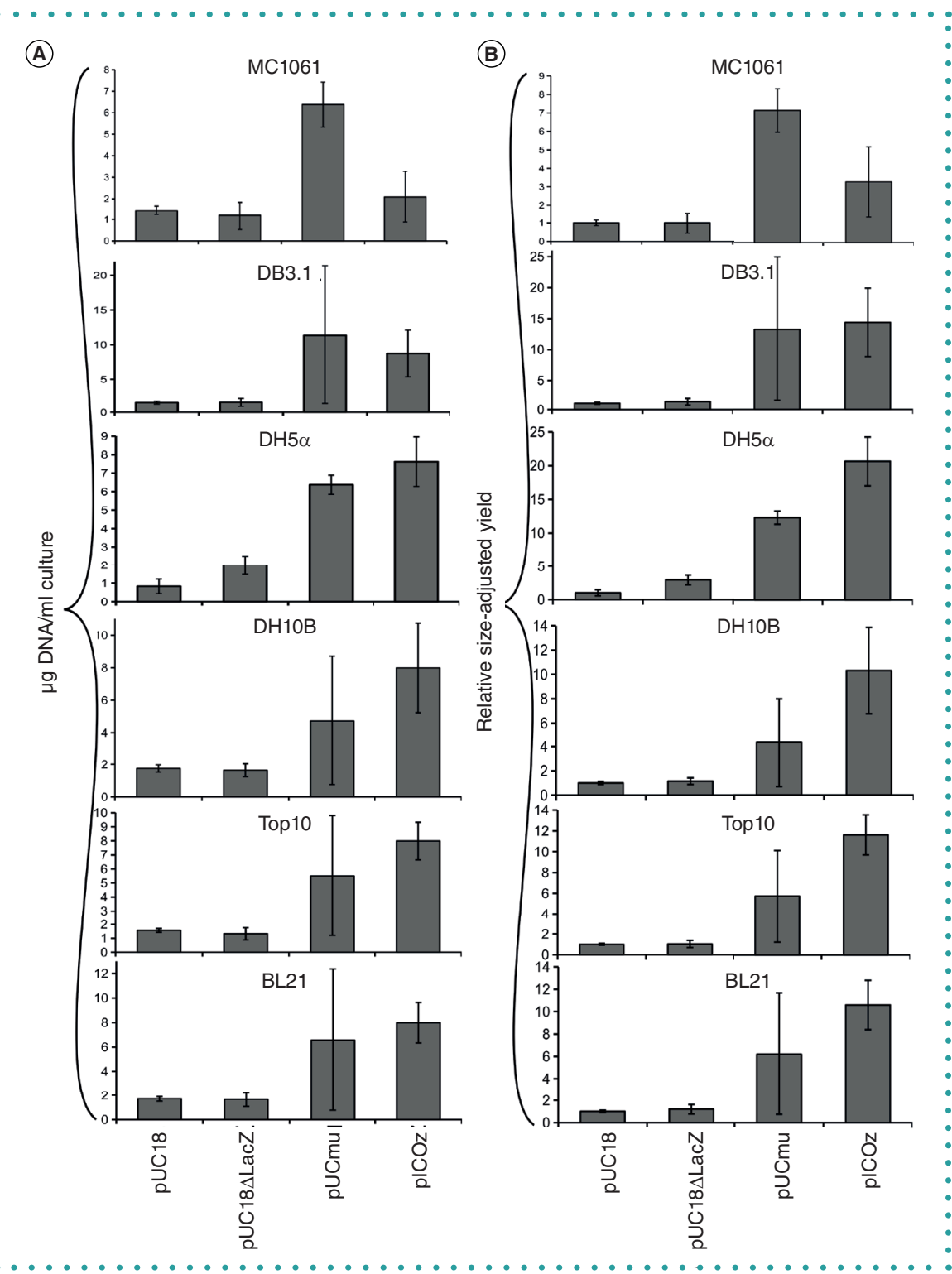

Figure 4. Yield comparisons of minimal plasmids vs parental plasmids in multiple $E$. coli strains. (A) Absolute yield ( $\mu \mathrm{g} / \mathrm{ml}$ overnight culture) for the four constructs. (B) Plasmid sizeadjusted relative yield (average pUC18 yield set to 1 ) and divided by relative size ( $\mathrm{pUC18}=1$, pUC18 $\mathrm{LacZ}=0.81, \mathrm{pUCmu}=0.62$ and $\mathrm{pICOz}=0.44$ ). The plasmid size-adjusted yield should be correlated with number of plasmid molecules extracted $/ \mathrm{ml}$ of overnight culture. Error bars represent $95 \%$ confidence intervals.

D By lucky coincidence, we managed to identify a random deletion mutant of the pUC variant of the $\mathrm{pMB1} O \mathrm{ORI}$, which shrunk the pUC ORI from $750 \mathrm{bp}$ to $616 \mathrm{bp}$. A minimal pUC-derived ORI of $674 \mathrm{bp}$ (GenBank: EU496091.1) has been described in the BioBrick system [18]. Sequence comparisons reveal alignment between pICOz and base 3-618 of the BioBrick pUC ORI. The alignment also revealed that the BioBrick pUC contains a few point mutations to eliminate restriction sites in the ORI. Our minimal backbone could in principle very easily be made completely synthetically, where all restriction sites in the backbone in theory could be eliminated and the MCS be further extended. This could be one very interesting future prospect for further development of the pICOz backbone as a standard IGEM 'part' for synthetic biology $[19,20]$. Our random deletion pUC ORI mutant is likely to be almost the most minimal variant of the $\mathrm{pUC}$ ORI that can be generated, since RNAll
(27-615 bp on the BioBrick genbank annotation) is absolutely needed, and the remaining upstream flanking bases (3-27 on the BioBrick genbank annotation) are most likely required for the expression of the RNAll. Despite being required for plasmid replication, RNAll is sometimes not included in the pUC ORI (pMB1) annotation (Figure 1). A minimal ORI from the low-copy plasmid pSC101 of only 220 bp has been described [21]. In theory it should be possible to shrink pICOz to $789 \mathrm{bp}$ with this minimal ORI if it works without additional sequences like pUC ORI depends on RNAll. With our $1185 \mathrm{bp}$, we are however already very close to the smallest plasmid ever found in nature (746 bp), and we usually need a high-copy plasmid and a selectable marker to have a useful cloning vector, which currently restricts further size optimization. Other use-cases could however require low-copy plasmids (e.g., for E. coli protein expression) and in those cases additional size optimizations such as the $\mathrm{PSC} 101 \mathrm{ORI}$ could be interesting. The selectable marker unconditionally adds at least 458 bp (promoter + coding domain sequence [CDS] + terminator), so it might be that we are already at the lowest limits of what can be obtained for a fully functional high-copy cloning vector in E. coli.

\section{Practical use-cases of a small cloning plasmid}

There are several potential use-cases for a tiny plasmid backbone. One very useful use-case is to use pICOz as an intermediate cloning plasmid for PCR-mediated mutagenesis and then clone the generated mutant into the expression vector. This has three major advantages: 1) The PCR only needs to amplify a small product (insert $+1 \mathrm{~kb}$ ) rather than the entire expression vector (typically insert $+5-6 \mathrm{~kb}$ for mammalian expression vectors); 2) there is no risk that the PCR amplification has caused any unintended modifications to the expression vector; and 3) since most expression vectors are ampicillin resistant, cloning from the zeocin-resistant intermediate $\mathrm{pICOz}$ vector reduces the risk of contamination from the parental plCOz vector. The $\mathrm{pICOz}$ and $\mathrm{pUCmu}$ vector backbones can also be interesting as 
eukaryotic expression vector backbones in some cases. However, adding a complete mammalian expression casette and SV40 origin of replication defeats the purpose of the tiny backbone since the few $\mathrm{kb}$ saved on the backbone will make little difference on the final size of the expression vector. There are however use-cases with much smaller expression casettes, for example CRISPR/ Cas9 guideRNA expression from the U6 promoter and terminator (e.g., pU6mu LMBP 09491 and pU6z LMBP 11144). Expression of these guide RNAs are also preferably transient, so we do not need the SV40 origin of replication. We have experienced that some cells are more easily transfected with small expression plasmids (e.g., electroporation of Jurkat T cells) and this has also been shown by others [12], which means that these small expression plasmids can have a practical use-case. There are however many more potential use-cases of these small vector back bones in many fields of molecular biology and we encourage creative use of this tool to develop novel downstream applications.

\section{FUTURE PERSPECTIVE}

We highly encourage others to further improve on our best attempt to generate a minimal core cloning plasmid. Distributed development has been shown to be an extremely powerful force in open source software development [22], and genetic material shows many commonalities with software in that it can be copied and reproduced very easily [23]. People developing this backbone further are naturally free to explore and adapt it in any way they see fit. An interesting future tactic would however be to further explore alternative ORI and selectable markers in this vector backbone to try to shrink it further. Also extending the MCS and making a synthetic 'un-cleavable' pICOz backbone is a very interesting idea for future development. Other optimization aspects than size and cloning properties could also be interesting. For example, nonantibiotic selectable markers (like $\mathrm{Zn}^{2+}$ [24], $\mathrm{Cu}^{2+}$ [25], $\mathrm{Ag}^{+}$[26] or high-salt [27] resistance) could be highly interesting to explore for $E$. coli cloning vectors.

\section{AUTHOR CONTRIBUTIONS}

Conceptualization JS; Methodology JS; Validation JS, WDS, KA; Formal Analysis JS;
Investigation JS, KA; Resources RB, MV; Data curation JS, WDS; Writing - original draft preparation JS; Writing - review \& editing RB; Visualization JS; Supervision RB; Project administration RB, MV; Funding acquisition RB.

\section{ACKNOWLEDGMENTS}

BCCM/GeneCorner for storage and plasmid information infrastructure.

\section{FINANCIAL \& COMPETING INTERESTS DISCLOSURE}

The authors have no relevant affiliations or financial involvement with any organization or entity with a financial interest in or financial conflict with the subject matter or materials discussed in the manuscript. This includes employment, consultancies, honoraria, stock ownership or options, expert testimony, grants or patents received or pending, or royalties.

No writing assistance was utilized in the production of this manuscript.

\section{OPEN ACCESS}

This work is licensed under the AttributionNonCommercial-NoDerivatives 4.0 Unported License. To view a copy of this license, visit http://creativecommons.org/licenses/ by-nc-nd/4.0/

\section{SUPPLEMENTARY DATA}

To view the supplementary data that accompany this paper please visit the journal website at: www.future-science. com/doi/suppl/10.2144/btn-2019-0014

\section{REFERENCES}

1. Mandecki W, Hayden MA, Shallcross MA, Stotland E. A totally synthetic plasmid for general cloning, gene expression and mutagenesis in Escherichia coli. Gene 94(1), 103-107 (1990).

2. Norrander J, Kempe T, Messing J. Construction of improved M1 3 vectors using oligodeoxynucleotide-directed mutagenesis. Gene 26(1), 101-106 (1983).

3. Vieira J, Messing J. The pUC plasmids, an M13mp7-derived system for insertion mutagenesis and sequencing with synthetic universal primers. Gene 19(3),259-268 (1982).

4. Jeffrey V, Joachim M. New pUC-derived cloning vectors with different selectable markers and DNA replication origins. Gene 100, 189-194 (1991).

5. Lin-Chao S, Chen W-T, Wong T-T. High copy number of the pUC plasmid results from a Rom/Rop-suppressible point mutation in RNA II. Mol. Microbiol. 6(22) 3385-3393 (1992).

6. VanEenoo C. Minimalism in art and design: concept, influences, implications and perspectives. J. Fine Studio Art. 2(1), 7-12 (2011)

7. de Saint-Exupéry A. Wind, Sand and Stars. Houghton Mifflin Harcourt, MA, USA.

8. Raymond ES. The Art of Unix Programming. Addison-Wesley Professional, MA, USA.

9. Spinellis D. Tool writing: a forgotten art? (software tools). IEEE Softw. 22(4), 9-11 (2005).
10. Kushner PJ, Baxter JD, Duncan KG et al. Eukaryotic regulatory elements lurking in plasmid DNA: the activator protein-1 site in pUC. Mol. Endocrinol. 8(4), 405-407 (1994)

11. Pauwels $K$, Abadjieva $A$, Hilven $P$, Crabeel $M$. A strong carbon source effect is mediated by pUC plasmid sequences in a series of classical yeast vectors designed or promoter characterization. Yeast 15(12), 1269-1274 (1999).

12. Hornstein BD, Roman D, Arévalo-Soliz LM, Engevik MA, Zechiedrich L. Effects of circular DNA length on transfection efficiency by electroporation into HeLa Cells. PloS One 11(12), e0167537 (2016).

13. Catanese DJ, Fogg JM, Schrock DE, Gilbert BE, Zechiedrich L. Supercoiled minivector DNA resists shear forces associated with gene therapy delivery. Gene Ther. 19(1), 94-100 (2012).

14. Ciok A, Dziewit L, Grzesiak J et al. Identification of miniature plasmids in psychrophilic Arctic bacteria of the genus Variovorax. FEMS Microbiol. Ecol. 92(4), fiw043 (2016).

15. Okonechnikov K, Golosova O, Fursov M, UGENE team. Unipro UGENE: a unified bioinformatics toolkit. Bioinforma. Oxf. Engl. 28(8), 1166-1167 (2012).

16. ISO B. 9001: 2008 Quality management systems. Requirements. Int. Organ. Stand. (2000).

17. Bryksin AV, Matsumura I. Overlap extension PCR cloning: a simple and reliable way to create recombinan plasmids. BioTechniques 48(6), 463-465 (2010).

18. Shetty RP, Endy D, Knight TF. Engineering BioBrick vectors from BioBrick parts. J. Biol. Eng. 2, 5 (2008).

19. Ellis T, Adie T, Baldwin GS. DNA assembly for synthetic biology. from parts to pathways and beyond. Integr. Biol. 3(2), 109-118 (2011)

20. Heinemann M, Panke S. Synthetic biology - putting engineering into biology. Bioinformatics. 22(22), 2790-2799 (2006).

21. Sugiura S, Ohkubo S, Yamaguchi K. Minimal essential origin of plasmid pSC101 replication: requirement of a region downstream of iterons. J. Bacteriol. 175(18), 5993-6001 (1993)

22. Raymond E. The cathedral and the bazaar. Knowl. Technol. Policy. 12(3), 23-49 (1999).

23. Pang TY, Maslov S. Universal distribution of component frequencies in biological and technological systems. Proc. Natl Acad. Sci. USA 201217795 (2013).

24. Mahapatra NR, Ghosh S, Deb C, Banerjee PC. Resistance to cadmium and zinc in Acidiphilium symbioticum KM2 is plasmid mediated. Curr. Microbiol. 45(3), 180-186 (2002).

25. Baker-Austin C, Dopson M, Wexler M, Sawers RG, Bond PL. Molecular insight into extreme copper resistance in the extremophilic archaeon 'Ferroplasma acidarmanus' Fer1. Microbiology 151(8), 2637-2646 (2005).

26. Sedlak RH, Hnilova M, Grosh $\mathrm{C}$ et al. Engineered Escherichia coli silver-binding periplasmic protein that promotes silver tolerance. Appl. Environ. Microbiol. 78(7), 2289-2296 (2012).

27. Guo Y, Winkler J, Kao KC. Insights on osmotic tolerance mechanisms in Escherichia coli gained from an rpoC mutation. Bioengineering. 4(3), 61 (2017). 